\title{
Physical Model Simulation: Influences the Shape of Breakwater Structures on the Coefficient of Transmission and Reflection
}

\author{
Pujianiki Ni Nyoman ${ }^{\mathrm{a}, *}$, Riska Dayanti ${ }^{\mathrm{a}}$ \\ ${ }^{a}$ Civil Engineering Udayana University, Kampus Bukit Jimbaran, 80361, Bali, Indonesia \\ Corresponding author: "pujianiki@civil.unud.ac.id
}

\begin{abstract}
Breakwater is used to break the wave energy that travels towards the beach. Part of the wave energy will be destroyed, transmitted, or reflected. The shape of breakwater affects the ability to break the wave energy. There are no researchers who have compared the effect of the shape of the breakwater structure on wave energy transmitted and reflected. This study aims to simulate the transmission coefficient $(\mathrm{Kt})$ and reflection coefficient $(\mathrm{Kr})$ of the breakwater in various forms. Physical models with a 1:100 scale model is used. A flap-type wave generator in a wave flume is used to generate the wave. Waves regularly move in one direction passed the model. The results showed an effect of the shape of the breakwater structure on $\mathrm{Kt}$ and $\mathrm{Kr}$. By increasing the wave steepness $(\mathrm{Hi} / \mathrm{L})$, $\mathrm{Kt}$ 's value will increase in the upright structure and decrease in the sloping structure. At the same time, the value of $\mathrm{Kr}$ tends to decrease when the wave steepness increases. The value of $\mathrm{Kt}$ is relatively smaller in upright structures than in sloping structures. By adding porosity to the structure, the Kt value will increase, followed by Kr's reduction. By increasing the crest B's width, Kt appears to increase, but the crest width does not significantly affect $\mathrm{Kr}$. $\mathrm{Kt}$ and $\mathrm{Kr}$ are significantly smaller if the breakwater structure is inclined towards the sea or inverted trapezium. This type of breakwater has never been encountered in the field before.
\end{abstract}

Keywords - Breakwater; transmission wave; reflection wave; porosity.

\section{INTRODUCTION}

The breakwater is a coastal structure that functions to break the wave energy that goes to the beach. Waves that propagate to shore when it comes to energy dampers, then some of the wave energy will be reflected (reflection), some will be transmitted to transmission waves, or wave energy will be destroyed (dissipation) by the wave breaking process. The wave energy magnitude depends on the incident wave's characteristics such as period, height and depth of the wave, type and geometric of the breakwater structure, and surrounding environmental conditions [1].

The breakwater is built to protect existing coastal facilities such as ports, tourist beach areas or can be used to protect coastlines from erosion and sedimentation. The breakwater is built from natural stone, concrete, or steel under the type of breakwater. According to its shape, the breakwater is divided into sloping breakwater and upright breakwater. Many studies have been carried out to obtain an optimal breakwater structure [2]-[7]. Johnny et al. [8] have tested the physical model of the submerged breakwater in the form of six sawteeth. The test results show that this sawtooth model can reduce the wave energy and has a refractive effect that can help the shoreline formation. While Zulkarnain and Anwar [9] researched the effect of freeboard on low-threshold breakwaters in reducing wave energy.

Many researchers have investigated the interaction of waves and breakwaters by changing the wave parameters or structures' dimensions. However, no researchers have yet compared the shape of the breakwater on the energy of waves transmitted and reflected. Wave reflection is usually expressed in terms of a wave reflection coefficient $(\mathrm{Kr})$. The value of $\mathrm{Kr}$ ranges from 1.0 for total reflection, and if no reflection occurs, the value of $\mathrm{Kr}$ is 0 . At the same time, the transmission wave is expressed by the transmission coefficient $(\mathrm{Kt})$ whose value depends on the ratio of the transmission wave height (Ht) to the incoming wave (Hi). The amount of wave energy that is dissipated (destroyed or damped) is the amount of incoming wave energy (Hi) minus the wave energy that is transmitted $(\mathrm{Ht})$ and reflected $(\mathrm{Hr})$ [10]. Wave height reduction was influenced by the wave steepness, relative freeboard, relative depth, and porosity [11].

Sigurdarson and Van De Meer [12] state that wave reflection from berm breakwaters is reasonably low, comparable to or lower than conventional rock structures. 
New reflection formulae have been developed, one for hardly and partly reshaping berm breakwaters and thoroughly reshaping berm breakwaters. Koley et al. [13] and Park et al. [14] conducted laboratory experiments. The reflection coefficient and run-up height of breakwaters are investigated for different widths and heights of the submerged structure with different distances between adjacent two breakwaters. They found that the reflection coefficient decreased as the wave steepness increased.

In this study, $\mathrm{Kr}$ and $\mathrm{Kt}$ were simulated using physical models in the laboratory. The relationship between models and prototypes uses a scale of 1: 100. The scale is defined as the ratio of the prototype's values and the parameter values used in the model. Dimensional numbers are used to express relations between parameters and describe the research results in determining dimensionless numbers, and dimensional analysis can be done.

\section{MATERIAL AND METHOD}

Under the objectives of the study, the variables studied were the breakwater ability to reduce wave runoff, which is affected by the wave period (T), incident wave height $(\mathrm{Hi})$, water depth (d), transmission wave height $(\mathrm{Ht})$, and reflection wave height (Hr). In this study, geometric and non-distortion models are used. A model with a non-distortion geometric similarity has the same shape characteristics between the model and prototype but has different size comparisons. The comparison between all lengths of models and prototypes is the same.

The determination of the geometric scale is adjusted to the flume tank's (see Figure 1) capability and capacity in the laboratory and considers the prototype's size. The width and height of the model are adjusted to the size of the flume used for the study so that the experimental scale obtained on the model is $n L=n H=100$. To determine the wave period (T) time scaling using Froude similarity uses the equation $N T$ $=\sqrt{ } 100=10$.

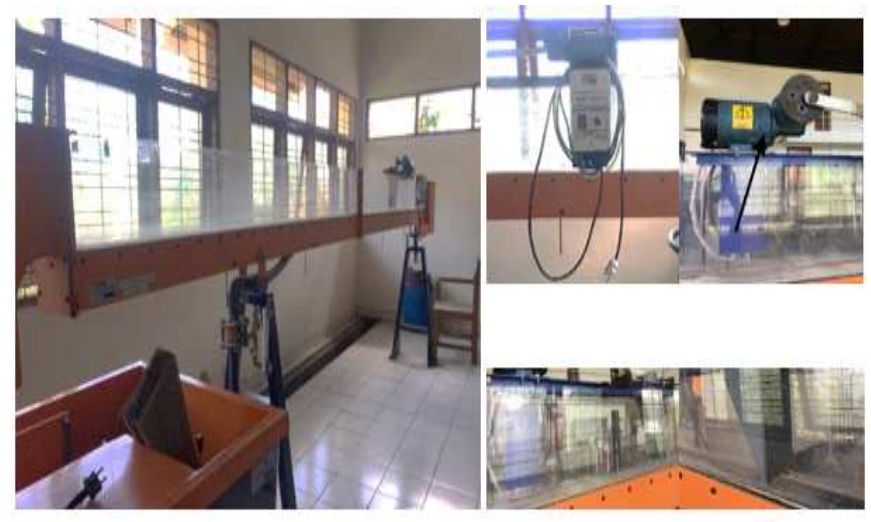

Fig. 1 Flume tank

With a scale of 1: 100, the breakwater model is made of wood placed in a strong wave flume so that it cannot move due to wave attack. Variations of each model can be seen in Table 1 and Figure 2.
TABLE I

VARIATION OF MODEL

\begin{tabular}{|c|c|c|c|c|}
\hline \multirow{2}{*}{ Model } & \multicolumn{3}{|c|}{ Structure } & \multirow{2}{*}{ Porosity } \\
\hline & Upright & Sloping & Crest width (B) & \\
\hline 1 & $\mathrm{x}$ & - & $3 \mathrm{~cm}$ & - \\
\hline 2 & $\mathrm{x}$ & - & $6 \mathrm{~cm}$ & - \\
\hline 3 & - & $\mathrm{x}$ & $3 \mathrm{~cm}$ & - \\
\hline 4 & & $\mathrm{x}$ & $6 \mathrm{~cm}$ & - \\
\hline 5 & $\mathrm{x}$ & - & $3 \mathrm{~cm}$ & $15 \%$ \\
\hline 6 & $\mathrm{x}$ & - & $6 \mathrm{~cm}$ & $15 \%$ \\
\hline 7 & - & $\mathrm{x}$ & $6 \mathrm{~cm}$ & $15 \%$ \\
\hline 8 & $\mathrm{x}$ & - & $3 \mathrm{~cm}$ & $25 \%$ \\
\hline 9 & $\mathrm{x}$ & - & $6 \mathrm{~cm}$ & $25 \%$ \\
\hline 10 & - & $\mathrm{x}$ & $6 \mathrm{~cm}$ & $25 \%$ \\
\hline 11 & - & $\mathrm{x}$ & $12 \mathrm{~cm}$ & - \\
\hline
\end{tabular}
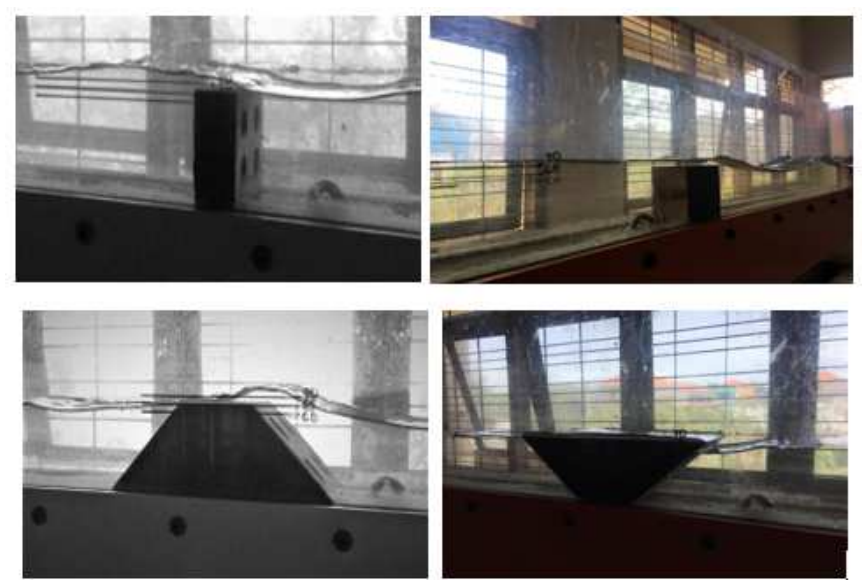

Fig. 2 Models

The model was made with a height of $6.5 \mathrm{~cm}$ placed at a depth of water $6-7 \mathrm{~cm}$ in a wave flume with a size of $20.00 \mathrm{x}$ $0.075 \times 0.20 \mathrm{~m}$ equipped with a flap-type wave drive. To determine the magnitude of porosity, the hole's area is divided by the outer surface without holes. The hole diameter is determined at $1.5 \mathrm{~cm}$ and $2.5 \mathrm{~cm}$; thus, the porosity value can be determined at $15 \%$ and $25 \%$. To examine the effect of the crest width, the 3 and $6 \mathrm{~cm}$ peak widths were determined. Meanwhile, breakwater model 11 is a type of breakwater with a slope facing the sea or inverted trapezium, this breakwater model has never existed in the field, so it is interesting to study.

The observation points are carried out in front of and behind the model, while the model is placed in the middle of the wave flume made the formed waves are stable. A wave dumper is used to reduce the wave energy at the side of the flume. The wave generator machine consists of the main engine, a potential that functions to regulate the disc's rotation time connected to the stroke to move the flap as a wave generator. Observations are made after the wave moves through the model. The engine shuts down after the observation is complete. The incoming wave height (Hi) is measured $5 \mathrm{~m}$ in front of the model, while the reflection wave height $(\mathrm{Hr})$ is measured in front of the structure, and the transmission wave height $(\mathrm{Ht})$ is measured behind the model. Tests were carried out for some variations into the water with a wave period of 0.6 - 1 second. 
The stages of model testing are described as follows:

- After the calibration has been completed, it is continued with model testing. The breakwater model is placed in the middle of the wave flume to receive incoming waves effectively. Then the specified water depth is measured according to the test scenario.

- After all component tools and models are ready, testing or running models are carried out. The test aims to obtain data on maximum wave height, minimum wave height, and wave height variations, and wave period.

- Wave height data obtained from the running model results are used to determine the incident wave height (Hi) using equation (2). Meanwhile, calculating the height of the reflected wave and the transmission of waves is used in equations (3) and (4).

- Calculate the reflection coefficient $(\mathrm{Kr})$ and the transmission coefficient $(\mathrm{Kt})$ using equations (5) and (6).

- Based on each model variation's coefficients, relationship graphs such as the steepness parameter of a wave and reflection coefficient or the influence of porosity $(\phi)$ are obtained with the reflection coefficient and other graphs to conclude from the results of the data analysis.

Partial standing wave profiles [15] can be formulated as follows:

$$
\eta=\frac{H_{i}}{2} \cos (k x-\sigma t)+\frac{H_{r}}{2} \cos (k x+\sigma t+\varepsilon)
$$

The above equation can be simplified so that it can determine the maximum water height and minimum water height in front of the barrier as follows:

$$
\begin{aligned}
& H_{i}=\frac{H_{\max }+H_{\min }}{2} \\
& H_{r}=\frac{H_{\max }-H_{\min }}{2}
\end{aligned}
$$

The transmitted wave height is calculated by:

$$
H_{t}=\frac{\left(H_{\max }\right)_{t}+\left(H_{\min }\right) t}{2}
$$

The parameters of wave reflection are expressed by the coefficient of wave reflection $(\mathrm{Kr})$ as follows:

$$
K r=\frac{H r}{H i}=\sqrt{\frac{E r}{E i}}
$$

The transmission coefficient $(\mathrm{Kt})$ is obtained from the following equation:

$$
K t=\frac{H t}{H i}=\sqrt{\frac{E t}{E i}}
$$

\section{RESULTS AND DISCUSSION}

In presenting the relationship between the steepness of waves and values of the reflection coefficient $(\mathrm{Kr})$ and transmission coefficient $(\mathrm{Kt})$, the dimensionless parameter used is $\mathrm{Hi} / \mathrm{L}$ as a parameter that can be presented wave characteristics. By determining the parameter $\mathrm{Hi} / \mathrm{L}$ as the $\mathrm{X}$ axis variable and the coefficient as the $\mathrm{Y}$-axis variable.

Simulation results of Model 1, where the model is the upright type with a crest width of $3 \mathrm{~cm}$ without porosity, are presented in Figure 3. From Figure 3, it can be concluded that the value of the reflection coefficient $(\mathrm{Kr})$ is inversely proportional to the steepness of the wave $(\mathrm{Hi} / \mathrm{L})$. We found that the reflection coefficient decreased as the wave steepness increased. This study's results are under Koley et al. [13] and Park et al. [14]. However, the transmission coefficient (Kt) is directly proportional to the steepness of the wave $(\mathrm{Hi} / \mathrm{L})$ means the more significant the steepness of the wave $(\mathrm{Hi} / \mathrm{L})$, the value transmission coefficient $(\mathrm{Kt})$ is increasing.

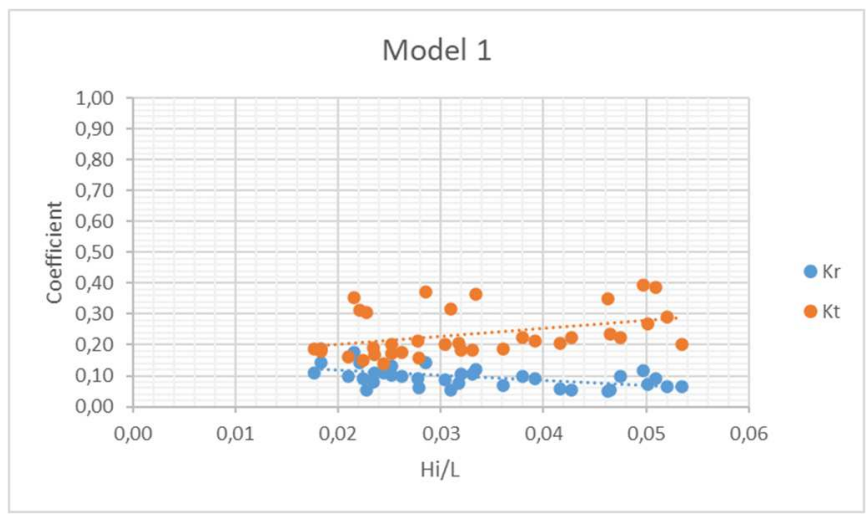

Fig. 3 Simulation results of Model 1 (Upright with crest width $3 \mathrm{~cm}$ )

Furthermore, the sloping breakwater model with the same crest width of $3 \mathrm{~cm}$ was also running with the waves' same parameters. The difference in the shape of the breakwater structure affects $\mathrm{Kr}$ and Kt's values, as shown in Figure 4. A higher Kt occurs in the breakwater Model 3 compared to Model 1. The value of the transmission coefficient on the graph ranges from $13.9 \%-39.5 \%$ for Model 1 . However, in Model 3 the value of the transmission coefficient ranges from $37.5 \%-63.9 \%$. This shows that the sloping breakwater has a larger Kt, which means that the sloping breakwater model will produce a more significant runoff than the upright breakwater model.

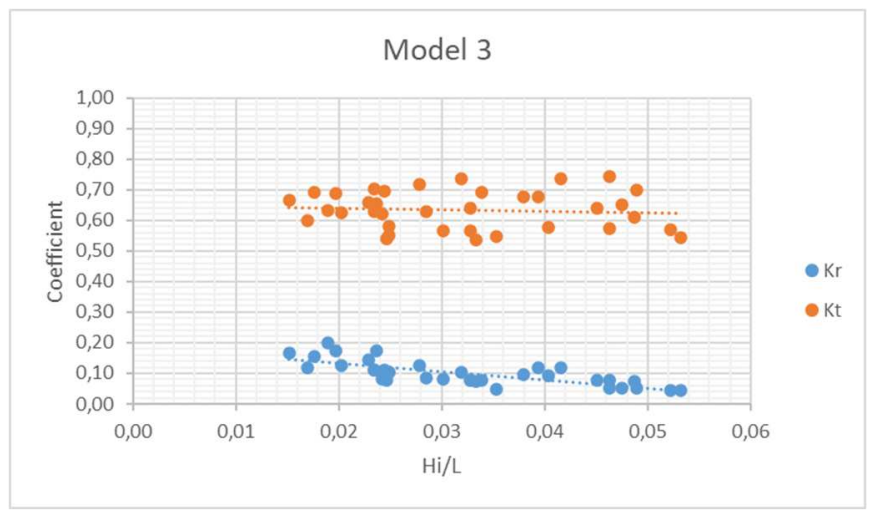

Fig. 4 Simulation results of Model 3 (Sloping with crest width $3 \mathrm{~cm}$ )

However slightly higher reflection coefficient $(\mathrm{Kr})$ occurs in Model 1 compared to model 3. The magnitude of the reflection coefficient values on this graph ranged from 5.0\%$18.52 \%$ in Model 1, whereas in Model 3, the reflection coefficient ranges from $4.35 \%-18 \%$. Both simulations show that $\mathrm{Kr}$ decreases with increasing wave steepness. This result agrees with Koley et al. [13], as shown in Figure 5. For structures that have a slope will give a relatively smaller $\mathrm{Kr}$ than the upright structure. However, unlike Kr's case, for sloping structures, the higher the wave steepness is followed by the decrease in $\mathrm{Kt}$, but for the upright structure, the greater the wave steepness, the $\mathrm{Kt}$ tends to increase. 

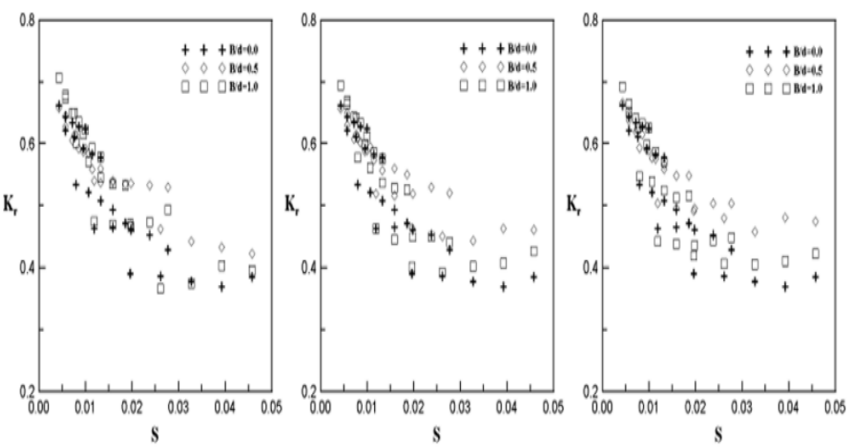

Fig. 5 Reflection Coefficient as a Function of the Wave Steepness [14]

Lorenzo et al. [11] also mention that the influence of the crest width (B) should be studied, as its effects on wave transmission are significant, according to previous studies by [16]-[18]. The effect of crest width (B) was also simulated in this study. The results of testing model 3 and model 4 are compared to see the effect of crest widening. The crest width is widened by $3 \mathrm{~cm}$ in model 3 to $6 \mathrm{~cm}$ in model 4 . As shown in Figure 6, by increasing the crest B's width, Kt appears to decrease, which means that the transmitted wave decreases as the crest width is increased. However, the crest width effect does not significantly affect $\mathrm{Kr}$, as shown in Figure 7.

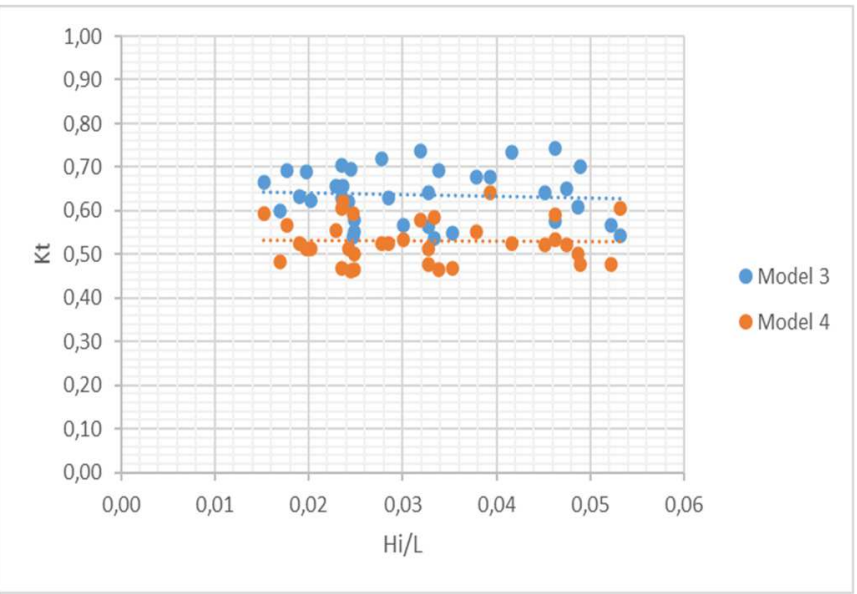

Fig. 6 Comparison Kt of Model 3 and Model 4 (increasing crest width)

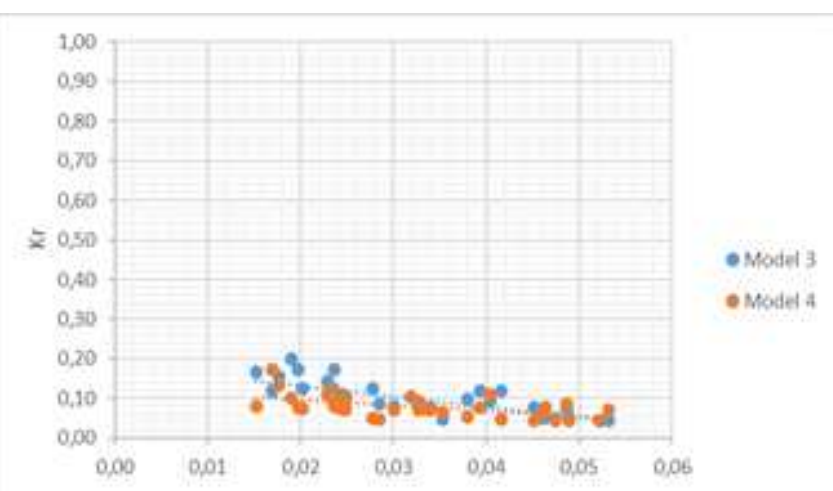

Fig. 7 Comparison Kr of Model 3 and Model 4 (increasing crest width)

Porosity also affects the magnitude of the transmitted wave, as Lorenzo et al. [11] conducted. They found that Kt decrease when the wave steepness rises. These effects seem to be higher in tests with non-porous units, as shown in Figure 8.
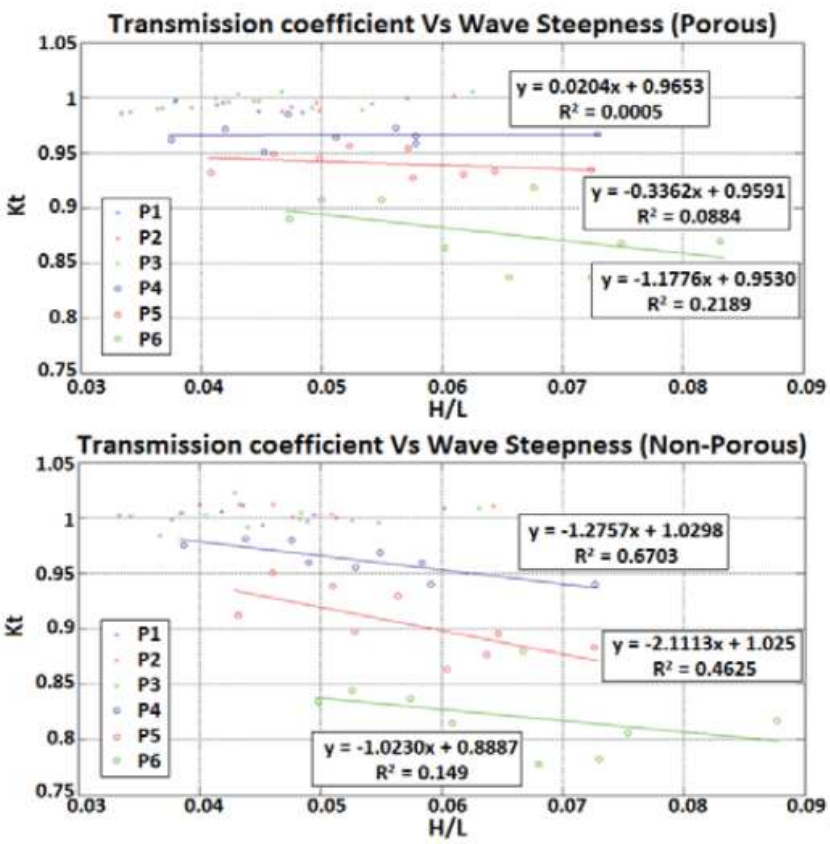

Fig. 8 Comparing transmission coefficient $(\mathrm{Kt})$ and wave steepness $(\mathrm{Hs} / \mathrm{L})$ with both porous and non-porous units [11]

The effect of porosity was also investigated in this study. The upright structure model, model 6 , and model 9 are compared to see the effect of porosity, by increasing the porosity, the transmission wave that occurs increases as shown in Figure 9.

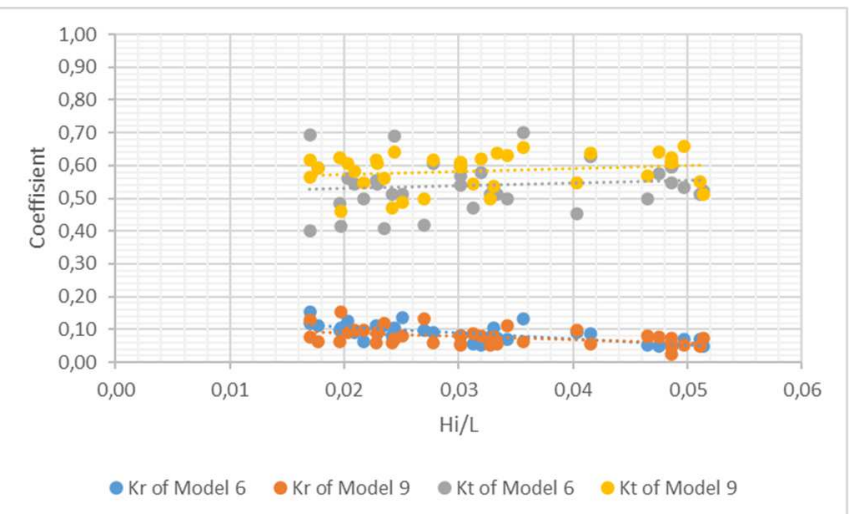

Fig. 9 Effect of porosity in $\mathrm{Kr}$ and $\mathrm{Kt}$

The reflection coefficient $(\mathrm{Kr})$ is inversely proportional to the steepness of the wave. It means the more significant the wave $(\mathrm{Hi} / \mathrm{L})$ steepness, the value the reflection wave coefficient $(\mathrm{Kr})$, gets smaller. Incoming waves cause this attack the breakwater with more steepness wave, the energy of the wave will be more transmitted into waves transmission. Therefore, the wave reflection height that occurs becomes smaller and affects the reflection coefficient $(\mathrm{Kr})$. The same effect is also shown in the sloping model. Especially for Model 11, the breakwater structure is given the inclination towards the sea or inverted trapezium. This type of structure has never been found in the field, giving rise to the desire to 
be investigated. We tried searching for similar research on the internet and in journals but were not found.

The model simulated at water depth $d=6-7 \mathrm{~cm}$. The high of the model is $6,5 \mathrm{~cm}$ then $\mathrm{d}=0,9 \mathrm{~h}-1,1 \mathrm{~h}$. From Figure 10, we can see no conclusive relationship between wave steepness $(\mathrm{Hi} / \mathrm{L})$ and $\mathrm{Kr}$ for each depth that can be extracted at the first level from this test. However, this shows that the $\mathrm{Kr}$ tends to decrease when the steepness of the wave rises. It seems that the value of $\mathrm{Kr}$ is relatively smaller than the previous model simulation. This kind of model still requires more simulations and investigation, especially the reflex wave at the structure's base because of the sloping structure toward the sea. Besides, no waves were transmitted in this experiment, as shown in Figure 10, even for the elevation of the water above the structure
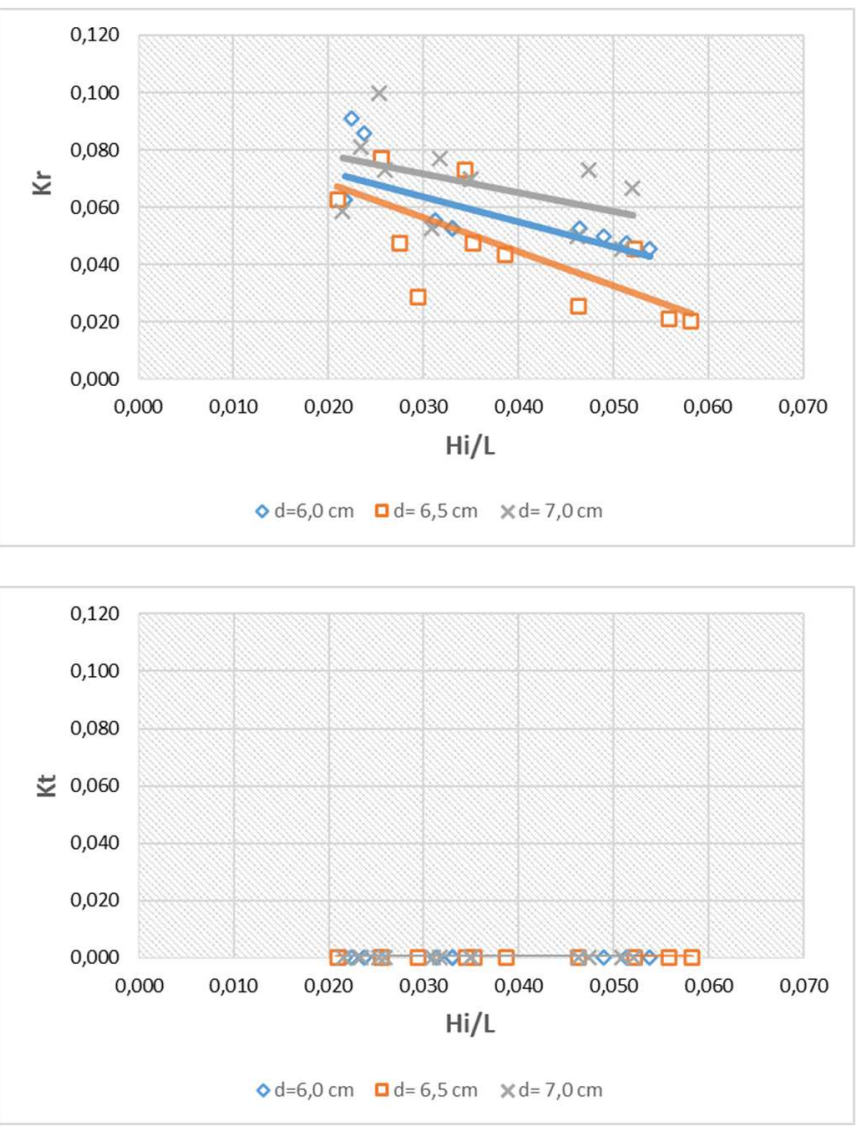

Fig. 10 Simulation of the Model 11

Thus, the structure of this model is suitable for reducing transmission waves and reflected waves. However, further research still needs to be done to see its broader influence. Of course, research related to structural stability needs to be done further.

\section{CONCLUSION}

The effect of structure shape and porosity on transmission wave $(\mathrm{Kt})$ and reflection wave $(\mathrm{Kr})$ has been investigated in this study. The shape of the structure examined is an upright and slope structure. For structures that have a slope will give a relatively smaller $\mathrm{Kr}$ than the upright structure. Increased wave steepness is followed by the decrease in $\mathrm{Kt}$ for sloping structures; however, for the upright structure, the more remarkable the wave steepness, the Kt tends to increase. By increasing the crest B's width, Kt appears to decrease, but the crest width effect does not significantly affect $\mathrm{Kr}$. By increasing the porosity on the structure, the transmission wave that occurs is increased.

The reflection coefficient $(\mathrm{Kr})$ is inversely proportional to the steepness of the wave. Incoming waves, because this attach the breakwater with more steepness wave, the wave's energy, will be more transmitted into waves transmission so that the wave reflection height that occurs becomes smaller and affects the value of the reflection coefficient $(\mathrm{Kr})$. The inverted trapezium breakwater structure simulation, which inclination towards the sea, shows that the $\mathrm{Kr}$ tends to decrease when the wave's steepness rises. No waves were transmitted in this experiment, even for the elevation of water above the structure. This kind of model still requires more simulations and investigation, especially the reflex wave at the structure's base.

\section{ACKNOWLEDGMENT}

We are grateful to the Institute for Research and Community Service of Udayana University (LPPM Unud) for funding this research. Through this research, we produced one final project for an undergraduate student.

\section{REFERENCES}

[1] Coastal Engineering Research Center, Shore protection manual Volume I, vol. 1. 1984.

[2] C. Liao, D. Tong, D. S. Jeng, and H. Zhao, "Numerical study for waveinduced oscillatory pore pressures and liquefaction around impermeable slope breakwater heads," Ocean Eng., vol. 157, no. February 2017, pp. 364-375, 2018, doi: 10.1016/j.oceaneng.2018.03.058.

[3] X. Li and W. Zhang, "3D numerical simulation of wave transmission for low-crested and submerged breakwaters," Coast. Eng., vol. 152, p. 103517, 2019, doi: 10.1016/j.coastaleng.2019.103517.

[4] E. Di Lauro, M. Maza, J. L. Lara, I. J. Losada, P. Contestabile, and D. Vicinanza, "Advantages of an innovative vertical breakwater with an overtopping wave energy converter," Coast. Eng., vol. 159, no. November 2019, p. 103713, 2020, doi: 10.1016/j.coastaleng.2020.103713.

[5] M. Buccino, M. Daliri, F. Dentale, A. Di Leo, and M. Calabrese, "CFD experiments on a low crested sloping top caisson breakwater. Part 1. nature of loadings and global stability," Ocean Eng., vol. 182, no. March, pp. 259-282, 2019, doi: 10.1016/j.oceaneng.2019.04.017.

[6] S. Bahena-Jimenez, E. Bautista, F. Méndez, and A. Quesada-Torres, "Wave reflection by a submerged cycloidal breakwater in presence of a beach with different depth profiles," Wave Motion, vol. 98, p. 102622, 2020, doi: 10.1016/j.wavemoti.2020.102622.

[7] Y. Yuksel, E. Cevik, M. R. A. van Gent, C. Sahin, A. Altunsu, and Z. Tugce Yuksel, "Stability of berm type breakwater with cube blocks in the lower slope and berm," Ocean Eng., vol. 217, no. September, p. 107985, 2020, doi: 10.1016/j.oceaneng.2020.107985.

[8] J. MT., Muchtasor, Pratikto Agus Widi, and Wahyudi, "Study Of Sinking Six-Tooth Saws Breakwater Physical Model," Din. Tek. Sipil, vol. 8, pp. 127-136, 2008.

[9] Z. Zulkarnain and N. Anwar, "Kajian Model Fisik Pengaruh Freeboard dan Susunan Buis Beton Sebagai Pemecah Gelombang Tenggelam Ambang Rendah (Pegar) Dalam Mereduksi Gelombang," Borneo Eng. J. Tek. Sipil, vol. 1, no. 2, p. 34, 2017, doi: 10.35334/be.v1i2.600.

[10] K. Horikawa, Coastal Engineering: An introduction to Ocean Engineering. University of Tokyo, 1978.

[11] L. Frau et al., "Effects of ultra-porous 3D printed reefs on wave kinematics," J. Coast. Res., vol. 1, no. 75, pp. 851-855, 2016, doi: 10.2112/SI75-171.1.

[12] S. Sigurdarson and J. Van Der Meer, "Design of berm breakwaters: Recession, overtopping and reflection," Coasts, Mar. Struct. Break. 2013 From Sea to Shore - Meet. Challenges Sea, vol. 1, no. September, pp. $64-74,2014$, doi: 10.1680/fsts.59757.0064. 
[13] S. Koley, K. Panduranga, N. Almashan, S. Neelamani, and A. AlRagum, "Numerical and experimental modeling of water wave interaction with rubble mound offshore porous breakwaters," Ocean Eng., vol. 218, no. July, p. 108218, 2020, doi: 10.1016/j.oceaneng.2020.108218

[14] S. H. Park, S. O. Lee, T.-H. Jung, and Y.-S. Cho, "Effects of submerged structure on rubble-mound breakwater: Experimental study," KSCE J. Civ. Eng., vol. 11, no. 6, pp. 277-284, 2007, doi: $10.1007 / \mathrm{bf0} 2885898$.

[15] B. Triatmodjo, Teknik Pantai. Yogyakarta: Beta Offset, 1999.

[16] N. Zhang, Q. Zhang, G. Zou, and X. Jiang, "Estimation of the transmission coefficients of wave height and period after smooth submerged breakwater using a non-hydrostatic wave model," Ocean Eng., vol. 122, pp. 202-214, 2016, doi 10.1016/j.oceaneng.2016.06.037.

[17] M. J. Choopanizade, M. Bakhtiari, and M. Rostami, "Wave transmission through the perforated half-depth block-made wall breakwater: An experimental study," Ocean Eng., vol. 215, no. December 2019, p. 107895, 2020, doi: 10.1016/j.oceaneng.2020.107895.

[18] I. Safak et al., "Wave transmission through living shoreline breakwalls," Cont. Shelf Res., vol. 211, p. 104268, 2020, doi: 10.1016/j.csr.2020.104268. 